\title{
Practice and compatability in 2-channel short-term memory
}

\author{
MEVILLE MORAY AND ANN JORDAN \\ UNIVERSITY OF SHEFFIELD, ENGLAND
}

Eleven Ss were required to listen to three pairs of digits presented dichotically. The member of each pair arrived simultaneously at opposite ears. They were asked to recall them either vocally, alternating between the ears, or manually on a keyboard which allowed them to respond to both ears at once. Contrary to Broadbent's earlier findings, very high levels of recall can be achieved in both conditions when the presentation rate is as high as 2 signals/ear/second.

Broadbent (1954) presented a $S$ with a dichotic memory span task in which three pairs of digits were presented to a listener, one item of each pair being presented to S's right ear at the same moment that the other was presented to his left ear. If the three pairs of digits arrived at a rate greater than about one pair/ $1-1 / 2$ sec., $S$ could only recall them correctly if they were recalled ear by ear (LLLRRR, hereafter called "Successive"), but not if they were recalled alternately from each ear (LRLRLR, called by Broadbent "in the correct order of arrival," and which we will call "Alternating"').

Moray (1960) queried Broadbent's conclusions about the time it takes to switch attention from one channel to another, and also the necessity for postulating a short-term memory store near the input end of the system to account for the success of the recall strategy called "Successive." Moreover, recently there have been several pieces of research which strongly suggest that retrieval is a very important part of transmission of information, and that the input/output compatibility is crucial for successful retrieval. (Sperling, 1960; Moray \& Barnett, 1965; Moray, Bates, \& Barnett, 1965; Fitts \& Seegar, 1954; Leonard, 1959). Also that practice can make a very big difference in performance in high-load transmission tasks (Mowbray \& Rhoades, 1959; Davis, Moray, \& Treisman, 1961)。 One feature of Broadbent's (1954) experiment stands out: it was impossible in his experiments for $\mathrm{S}$ to respond to the signals "in the actual order of arrival," for this would have necessitated them either saying or writing two digits at once. The experimental situation was one which demanded the serializing of a parallel input in order for responses to be made. Retrieval was therefore difficult.

The following experiment was designed to investigate the role of practice and compatibility in dichotic memory span tasks under optimal retrieval conditions.

\section{Method and Procedure}

Ss listened to lists of three pairs of digits chosen from the numbers $0-9$. In each set of three pairs no digit was repeated. Otherwise the lists were chosen randomly. The pairs were presented over headphones arranged for dichotic presentation. The left ear received one member of each pair at the same time that the right ear received the other. Simultaneity was checked and any nonsynchronous pairs re-recorded. The lists were presented at two pairs per second ( $=2$ signals/ear/second)。 A Brennell Mk. $\mathrm{V}$ tape recorder and Brown Type $\mathrm{K}$ $50 \mathrm{ohm}$ headphones were used to present the stimuli. $S$ received one list of three pairs every $15 \mathrm{sec}$. During the following 15 sec. $\mathrm{S}$ had to record his response.

Ss were required to recall either by speaking, alternating from ear to ear (LRLRLR response), called hereafter the Vocal Alternating condition, in which case the experimenter wrote down their responses; or by means of a keyboard which allowed them to press two keys simultaneously, one with the right hand (for the right-ear message) and one with the left hand (for the left ear message), called hereafter the Manual Simultaneous condition. The keyboard was that of a "Palantype" machine, which is a European version of the "Stenotype" machine, normally used for highspeed dictation. Essentially it consists of a typewriter in which the keys are arranged to match the positions of the fingers, and in which if two keys are pressed simultaneously two figures are printed side by side. Keys were allocated to the numbers 0-9 for each hand. The $S$ was not allowed to see the output tape from the Palantype.

Ss were 11 students and research workers of the Sheffield University Department of Psychology, aged between 18 and 35 .

Ss attended two sessions, one for practice and one for experimental purposes.

In the Practice session they received 25 lists with Manual Simultaneous output, 25 with Vocal Alternating, 25 with Vocal Alternating and 25 with Manual Simultaneous. There was a short rest period between each group of 25 lists. In the experimental session the order was 25 Vocal, 25 Manual, 25 Vocal, 25 Manual.

\section{Results}

Because of the high inter-S variability the results of each $\mathrm{S}$ for 50 lists are presented individually in Table 1 .

\section{Discussion}

Firstly, the two handed output condition allows very high scores to be obtained. Once scores are over $90 \%$ we are in the same range that is seen in the LLLRRR condition in the earlier experiments, and are indeed so 
Table 1. Percentage totally correct lists based on fifty lists per subject in each response condition

\begin{tabular}{lcc} 
& \multicolumn{2}{c}{ Response Condition } \\
\cline { 2 - 3 } Subject & Manual Simultaneous & Vocal \\
\hline 1 & 88 & 74 \\
2 & 92 & 92 \\
3 & 66 & 42 \\
4 & 36 & 42 \\
5 & 64 & 26 \\
6 & 62 & 40 \\
7 & 88 & 68 \\
8 & 84 & 88 \\
9 & 90 & 82 \\
10 & 50 & 28 \\
11 & 66 & 68 \\
\hline & 71.5 & 59.1 \\
Mean \% & $35.72 / 50$ & $29.54 / 50$ \\
Mean (Raw Scores) & 8.81 & 11.53 \\
s.d. (Row Scores) & &
\end{tabular}

near to perfect recall that the shortfall can easily be accounted for on the basis of acoustic confusion between signals and the lack of experience in making the motor responses required. Secondly, even when giving the Vocal Alternating responses, Ss are performing at a much higher level than in any previous experiments. Broadbent (1954) and Moray \& Barnett (1965) both found only about $20 \%$ correct in the Alternating recall condition at $2 /$ ear/second presentation.

The first conclusion that we may draw from the data is that yet again the very great importance of compatible input-output relationships has been demonstrated with respect to the optimizing of information transmission. There remains the difficulty in accounting for the enormous discrepancy in the Vocal Alternating condition between this study and earlier ones.

A close examination of Broadbent's original procedure reveals that in his 3-pairs-per-list condition half his Ss received only 10 lists in all, and the other half 24 lists in all in which they could give the Vocal Alternating response to a simultaneous dichotic imput. Similarly Moray and Barnett's Ss received only 20 lists in which they were explicitly asked to recall with Vocal Alternating responses, of which half were at 2 pairs/second and half at 1 pair/second. Clearly neither of the previous studies even begins satisfactorily to explore the performance levels to which practice might give rise.

In the present study Ss received 50 practice lists under the Manual Simultaneous response condition and 50 practice lists under the Vocal Alternating response condition. They then received a further 50 of each in the experimental session. In the practice sessions the total correct for each response condition is only (on the average) $13 \%$ lower than the experimental condition which gives levels of performance about twice those previously found.

The role of practice is underlined by the fact that in a more recent experiment a $\mathrm{S}$ who in his first run of 20 Manual Simultaneous responses only reached $30 \%$ correct reached $80 \%$ in the next run. After very little practice there is little or no difference between any of the conditions, although our impression is that the LRLRLR condition, whether manual or vocal, is probably subjectively the hardest of all. In a control experiment using the same Ss the Manual Successive (LLLRRR) condition gave the same performance as all previous experiments using Vocal Successive have found, namely an average of $90 \%$ correct at least.

The interpretation of Broadbent's (1954) experiment thus becomes that with 2-channel input of messages consisting of pairs of digits some part of the system is overloaded if there is only a single output channel if the messages arrive at more than about $6.64 \mathrm{bits} /$ second (=1 pair per second), in unpractised Ss. He rightly interpreted the effect as relating to the funnelling effect of 2-channel input into single channel output, i.e., in some way relating to the processing of parallel messages into a serial form.

The present study shows (a) that with practice this recoding becomes much more fluent, and (b) that if parallel-to-serial processing is not needed, but merely the labelling of messages as to which input/output line they are using, and if compatible output lines are provided, then no such parallel to serial recoding is required, and the signal transmission rate can be very greatly increased.

\section{References}

Broadbent, D. E. The role of auditory localisation and attention in memory span. J. exp. Psychol., 1954, 47, 191-196.

Broadbent, D. E., \& Gregory, M. Stimulus set and responses set: the alternation of attention. Quart. J. exp. Psychol., 1964, 16, 309-318.

Davis, R., Moray, N., \& Triesman, A. Imitative responses and the rate of gain of information. Quart. J. exp. Psychol., 1961, 13, 79-89.

Fitts, P., \& Seegar, C. M. S-R compatability: spatial characteristics of stimulus and response codes. J. exp. Psychol., 1953, 46, $199-210$

Leonard, J. A. Tactual choice reactions. I. Quart. J. exp. Psychol. $1959,11,76-83$.

Moray, N. Broadbent's filter theory: Postulate $H$ and the problem of switching time. Quart. J. exp Psychol., 1960, 12, 214-220.

Moray, N., \& Barnett, T. Stimulus presentation and methods of scoring in short-term memory experiments. Acta Psychologica. $1965,24,253-263$.

Moray, N., Bates, A., \& Bamett, T. Listening in the four-eared man. J. Acoust. Soc. Amer., 1965, 38, 196-201.

Mowbray, G. H., \& Rhoades, M. V. On the reduction of choice times with practice. Quart. J. exp. Psychol., 1959, 11, 16-23.

Sperling, G. The information available in brief visual exposures. Psychol. Monogr., 1960, Vol. 74. No. 11 (Whole No. 498) 